\title{
VIOLÊNCIA SEXUAL: ENTENDIMENTOS E INCONCLUSÕES
}

Ianne Ribeiro Gomes do Nascimento - Universidade Federal de Campina Grande (UFCG), iannergn@hotmail.com

PALAVRAS-CHAVE: Violência sexual. Ensino. Aprendizagem. Infância.

\section{INTRODUÇÃO}

Na contemporaneidade os casos de violência sexual tornaram-se um objeto de estudo para muitos pesquisadores, necessitando de intervenções nas diferentes atribuições na sociedade. Pois esse tipo de crime ainda é vivido por sigilo, vergonha e culpa. A criança vítima de abuso sexual apresenta grandes dificuldades em distinguir um ato de carinho do ato abusivo. Com isso, para ser compreendido esse tipo de violência a família e escola precisam estar preparadas para distinguir esse problema, buscando identificar a prevenção do abuso sexual infantil. Para promover a prevenção do abuso sexual infantil é preciso elaborar varias formas de autoproteção, obtendo habilidade no caso para que assim seja analisado o caso abusivo, para auxiliar a criança a se proteger.

Nesse sentido, o presente trabalho visa apresentar as primeiras discussões sobre violência sexual e seu desenvolvimento no processo de aprendizagem desde a infância e a idade adulta, a partir da revisão bibliográfica. Pautaremos em alguns autores com o objetivo de descrever o estado do conhecimento acerca da violência sexual. Na abordagem do tema, procurar-se-á, primeiramente, verificar a presença do conceito de violência sexual, na literatura para buscar os indícios de sua relação com a aprendizagem de universitários. Para tanto, serão selecionados textos contemporâneos, entre livros e artigos, em que o tema é discutido.

\section{METODOLOGIA}

O trabalho ora apresentado é de natureza qualitativa com uso de profunda revisão bibliográfica do tema escolhido. Para Lakatos (2001), a pesquisa bibliográfica compreende “toda a bibliografia já tornada pública em relação ao tema de estudo (...). Sua finalidade é colocar o pesquisador em contato direto com tudo o que foi escrito, dito ou filmado sobre determinado assunto" (LAKATOS, 2001, p. 183). Através desta pesquisa é possível analisar e refletir sobre o tema, tendo em vista vários autores, sendo realizada através de consultas a 
livros, revistas, artigos, dissertações e outros tipos de documentos que abordam o assunto em questão, além da pesquisa na internet e a elaboração do estado do conhecimento em que fizemos os estudos mediados pela Tabela de Análise de Textos Acadêmico-Científicos, segundo as Dimensões de Pesquisa propostas por Novikoff - TABDN (2010).

\section{DESCRIÇÕES, RESULTADOS, INTERPRETAÇÕES}

Alguns conceitos de violência sexual são postos para se instigar a curiosidade para que no decorrer das explanações, as descrições possam ganhar atenção para se pensar nas possíveis causas. As definições caracterizam o sistema de violência contra crianças e adolescentes. Dessa forma, os termos abuso ou maus-tratos contra crianças e adolescentes são, por exemplo, usados para caracterizar negligência, violência física, psicológica ou sexual de maneira intencional realizada por alguém em estágio de desenvolvimento superior que usa o seu poder, confiança ou força, para colocar a criança em situações nas quais não possua condições maturacionais, biológicas e psicológicas de enfrentamento.

A partir desse entendimento, são apresentados os principais fatores que fazem surgir, desenvolver e manter o fenômeno do abuso sexual: reprodução das experiências de violência familiar vivida na infância do agressor, desajustes familiares como problemas psíquicos e alcoolismo, e aspectos sociais e econômicos, como a desigualdade e dominação de gênero e de gerações (HABIGZANG; LUÍZA ; CAMINHA, RENATO, 2004, p. 213)

O abuso sexual, em síntese, caracteriza-se por qualquer ação de interesse sexual de um ou mais adultos em relação a uma criança ou adolescente, podendo ocorrer tanto no âmbito intrafamiliar - relação entre pessoas que tenham laços afetivos, quanto no âmbito extrafamiliar - relação entre pessoas que não possuem parentesco.

O abuso sexual e suas consequências sobre a saúde da vítima "são primeiramente uma violação dos direitos humanos, não escolhendo cor, raça, credo, etnia, sexo e idade para acontecer" (CUNHA; SILVA; GIOVANETTI, 2008, p. 245).

Silva (2000) fez uma revisão da literatura sobre os efeitos da desordem do estresse pós- traumático e apontou seis elementos comuns a pessoas que experimentaram o TEPT: reexperimentação de memórias intrusivas e persistentes ligadas ao trauma; exposições compulsivas a situações que lembram o trauma; impedimento incessante à exposição de situações específicas, usualmente ligadas à emoção do trauma experimentado e um entorpecimento às reações emocionais, de modo geral; diminuição da capacidade de usar 
linguagem falada, substituindo esta por gestos como guia para a ação; distúrbios ligados à desatenção, tais como desconcentração, discriminação de estímulo, alterações no mecanismo da defesa psicológica e na identidade pessoal; e, por último, alterações na identidade pessoal.

Os sintomas construídos durante uma experiência traumática afetam não somente os pensamentos do indivíduo, mas a sua memória, o estado de consciência e todo o campo de ação, de iniciativa e de objetividade na vida. Muitas vítimas criam uma área de proteção em volta de si que as impede de continuar com a vida normal. Uma vítima de violência física, seja ela estupro ou pancadas, evita sair de casa, tem medo de andar sozinha, rejeita sexo ou qualquer contato físico (SILVA, 2000, p. 32).

Para Romaro e Capitão (2007) as diversas formas de violência ou abuso afetam a saúde mental da criança ou do adolescente, justamente por se encontrar em um processo de desenvolvimento psíquico e físico. Os efeitos são danosos em diferentes aspectos: educacional, social e orgânico.

\section{CONSIDERAÇÕES FINAIS}

Ao revisar a literatura sobre o tema em questão, observamos que o abuso sexual que é praticado contra uma criança, adolescente ou adulto gera enormes prejuízos para sociedade, uma vez que dependendo da fase psicossexual, a vítima abusada sexualmente sofre no âmbito psicofisicamente, emocionalmente e cognitivamente, de modo a afetar a família, a sociedade em geral.

Os autores aqui estudados, oriundos de áreas como sociologia, psicologia, psicanálise e educação apresentam ao longo da discussão teórica as ações de prevenção ao abuso sexual infantil, configurando-se os diversos contextos em que o abuso sexual se institui. Nesse sentido, cada área/autor descreve situações abusivas, mas, cabe destacar que poucos abordam a vida dessas crianças em sala de aula. A discussão não aprofunda a relação entre a violência sexual e o processo de ensino aprendizagem.

Para promover uma redução de abuso sexual infantil, na vida dessas crianças é preciso abordar a temática com diversas informações, para que assim empregue apoio em relação de uma forma geral conceituando diversos pontos em cada estudo permita identificar a necessidade de produzir o entendimento de violências contra crianças e adolescentes que é um fenômeno universal que atinge todas as idades e níveis sociais. 
Os textos estudados instigam a revisão da literatura acerca da violência sexual no âmbito da Pedagogia critica social para se compreender os casos e poder contribuir com a discussão sobre o assunto.

Baseada nessa experiência sobre diferentes aspectos das literaturas foi possível aprender na realização desse trabalho o foco da prevenção ao abuso sexual infantil com a necessidade de produzir entendimento sobre alguns aspectos no desenvolvimento de crianças vítimas do abuso sexual de uma forma mais abrangente, podendo incluir a prevenção como ferramenta teórico-metodológica para professores - nossa motivação para estudos futuros.

\section{REFERÊNCIAS}

AMAZARRAY, Mayte Raya; KOLLER, Silvia Helena. Alguns aspectos observados no desenvolvimento de crianças vítimas de abuso sexual. Psicol. Reflex. Crit., Porto Alegre, v. 11, n. 3, p. 559-578, 1998

In<http://www.scielo.br/scielo.php?script=sci_arttext\&pid=S0102-

$79721998000300014 \& \operatorname{lng}=\mathrm{en} \& n r m=i s o>$. Acesso em 27 Mar. 2017.

ARCARI, C. (2013). Pipo e Fifi: Prevenção de violência sexual na infância. Acessando em 20 de setembro 2013. http://www.pipoefifi.org.br/home.html

BARBOSA, C.M.T.M. O conceito de infantil na psicanálise e sua relação com a clínica de Lacan.2003. 157f. Dissertação (mestrado em psicologia da saúde) - Universidade católica Dom Bosco.

FLORENTINO, B.R.B. As possíveis consequências do abuso sexual praticado contra crianças e adolescentes. Fractal: Revista de Psicologia, v. 27, n. 2, p. 139-144, 2015.

GENARI, F. TADEI G. B. Do miniadulto ao ser criança: discussões sobre a infância e a constituição da psicologia do desenvolvimento e da aprendizagem. In TADEI, Gescielly Barbosa da Silva, SOUZA, Márcia Regina de . Problemas e dificuldades de aprendizagem na infâncial Storer. Maringá - PR, 2012, p.30-37.

HABIGZANG, Luíza F. \& Caminha, Renato M. Abuso sexual contra crianças e adolescentes: conceituação, 2004. Psico-USF, v. 10, n. 2, p. 213-214, jul./dez. 2005. In< http://www.scielo.br/pdf/pusf/v10n2/v10n2a14.pdf> Acesso em 10 de jun., 2017.

KENNY, M. C. \&WURTELE, S. K. (2010). Children' S abilities to recognize a “good" person as a potencial perpetrator of shildhood sexual abuse. Child Abuse \&Neglet, 34, 490495.

TADEI, Gescielly Barbosa da Silva, SOUZA, Márcia Regina de . Problemas e dificuldades de aprendizagem na infância/ Storer. Maringá - PR, 2012. 224 p. 
ZAVARONI, D.M.L.; VIANA, T.C.; CELES, L.A.M. A constituição do infantil na obra de Freud. Estudos de psicologia. V.12, N.1, P.65-70, 2007. 